\title{
Incidence of Hip Dysplasia in Domestic Cats - Study With 86 Animals
}

\author{
Ana Carolina Valentim Hespanha ${ }^{1}$, Danilo Marques*2, Ana Carina Saito Silvestre ${ }^{3}$, Paula Fratini ${ }^{4}$, José Fernando \\ Ibañez $^{5}$
}

${ }^{1}$ Department of Veterinary Clinic Autonoma, Brazil

${ }^{2}$ Department Orthopedic, nclivepa Hospital, Brazil

${ }^{3}$ Department of Veterinary Clinic Autonoma, Brazil

${ }^{4}$ Biologist, Postdoctoral studies at the University of São Paulo, Brazil

${ }^{5}$ Teacher of veterinary orthopedics at the Federal University of Paraná, Brazil

Received: 制: August 25, 2018; Published: 制 September 12, 2018

*Corresponding author: Danilo Marques, Department Orthopedic, nclivepa Hospital, Av. Miguel Estefno, Brazil, 2800

\begin{abstract}
Although a well-studied joint disease in dogs, hip dysplasia (HD) in cats is a relatively neglected condition. There remains some controversy as to the clinical manifestations and incidence of hip dysplasia in domestic cats. The clinical manifestations in cats differ from those in dogs - the literature indicates that the main clinical signs are reluctance/ difficulty jumping. There is, therefore, great interest in identification of clinical signs to allow early diagnosis and treatment to avoid chronic problems. As in dogs, definitive diagnosis in cats is by radiographic examination. The aim of this study was to evaluate the incidence of hip dysplasia in adult cats using radiographic examination and to correlate radiographic findings with Norberg Angle. Eighty - six cats over one year old were evaluated in which the Norberg angle, articular and morphological alterations were evaluated. Thirty-five (35/86) cats showed some sign of discomfort during physical examination. Nine owners $(9 / 56)$ of the incongruent cats reported some behavioral changes during anamnesis. The results of this study suggest that there is a high incidence of feline hip dysplasia in this study and the Norberg Angle should be used in conjunction with other findings in the diagnosis of hip dysplasia.
\end{abstract}

Keywords: Feline; Hip Dysplasia; Clinical Signs; Diagnosis; Radiology

\section{Introduction}

Great advances have been made in feline medicine in the last twenty years. As a consequence of better care and early recognition of illness by owners, cats are now more healthy and are living longer [1]. Joint diseases have been widely studied in dogs, but less so in cats [2], because it was thought feline arthroses were rare [3]. Joint disease is now more often diagnosed in cats $[4,5]$ and is thought to be responsible for chronic pain in many untreated cats [6], directly altering their quality of life [2]. Although the general principles of orthopedics are the same for any species, the anatomy, function [1] and behavior of cats does differ from that in dogs [3]. Hip dysplasia is the abnormal fit of the acetabulum and femoral head, and is usually bilateral. It starts with varying degrees of looseness of the surrounding soft tissues, articular instability, and deformities of the femoral head, neck and acetabulum that result in osteoarthritis [7]. In cats it was first described in Maine Coones but is also reported in Persian and exotic breeds [8]. In a study including a variety of different breeds, an incidence $6.66 \%$ of hip dysplasia (HD) was reported [9].

It is likely that this low incidence of HD in cats compared to dogs is a real finding based on the fact that it is often diagnosed incidentally on radiographic examination $[1,10]$. The low incidence in this species may be associated with its small and varied genetic heritage [1]. However, higher incidences of HD were observed by [11] and Medeiros Júnior et al. [12] who reported incidences 32\% and $40 \%$, respectively. Clarke and Bennet in 2006 also reported that HD represents $22 \%$ of cases of pelvis osteoarthritis in cats. In cats, HD is usually mild and bilateral, and there are fewer radiographic signs of degenerative joint disease than in dogs [11]. Clarke and Bennett [4] reported that the hip osteoarthritis is common in cats, affecting $48 \%$ of dysplastic animals; although in most cases there were no clinical signs of HD. There is no sex predisposition for the condition [12] and pure breeds are predisposed [1]. HD may be a cause of pain and reduced activity [13]. Since cats often mask pain and clinical signs by adjusting their lifestyle, owners may miss behavioral changes associated with HD [1] or dismiss clinical signs as ageing changes [14].

Capsular thickening, synovial effusion, crepitus, and decreased range of motion are unusual findings during clinical examination in cats with HD $[4,14]$. The main clinical finding is lameness, and this may not be present in all cases. Pain can be difficult to assess in cats, 
since most do not tolerate manipulation well, making interpretation of joint manipulation difficult $[4,14]$. In addition, cats rarely vocalize in response to pain, typically showing behavioral manifestations of pain [13]. Parameters such as heart and respiratory rates are poor indicators of pain in cats [14]. Cats with chronic pain tend to show nonspecific changes such as reduced activity, changes in urination (loss of litter box training, etc.), reduced grooming, aggressiveness and / or become withdrawn $[14,15]$. Due to the uncooperative nature of cats and their reluctance to roam freely in a strange environment (favoring hiding in corners or under furniture), clinical assessment of gait is difficult [1]. Often history is essential in identification of gait changes in cats $[1,5]$.

The owner plays a vital role in the diagnosis, since cats with HD may show only reduced activity and behavioral changes $[3,5,16]$. Therefore, owners of adult and geriatric cats should be encouraged to complete an annual clinical questionnaire to identify chronic pain or behavior changes so that early recognition of change is possible [3].Unfortunately, due to the free roaming lifestyle of most domestic cats, an accurate history is not always available [1]. It may be helpful to request videos of the cat in its natural environment for assessment [1].Diagnosis of HD should be based on radiographic examination [5,7] since signs of hip dysplasia may be absent from anamnesis and clinical examination [8]. In order to obtain diagnostic radiographs sedation is required for proper positioning [7]. The standard radiographic projection for evaluation of hips is a ventrodorsal pelvis with the femurs extended parallel to one another and to the spine, with medial rotation so that the patellae overlie the trochlear grooves [7]. In dogs, the minimum age for radiogaphic examination for diagnosis of HD is 24 months $[7,17]$ and the severity of disease is assessed by morphologic evaluation of joint structures, degree of degenerative joint disease and measurement of the Norberg angle.

The Norberg angle is the angle formed by a line connecting the centers of both femoral heads and one drawn between the center of a femoral head and the craniodorsal rim of the acetabulum on the same side [17]. In some cats this index is not a useful measure of whether an animal will develop hip incongruence. Clarke and Bennett recorded Norberg angles of 87.6 degrees in dysplastic cats compared to 99.2 degrees in cats with normal hip joints. Radiographic signs common to all species are shallow acetabulae, incongruity between the femoral head and acetabulum with varying degrees of dislocation, deformation of the femoral head and neck and signs of arthrosis in chronic cases [18]. Patsikas et al. [19] noticed dislocation or subluxation of the hip joint; insufficient development of the craniolateral acetabular edges; deformation of the contours of the subchondral bone of the acetabulum; shallow acetabulum and secondary degenerative changes in the femoral head and neck in cats with HD.

However, Patsikas et al. [8,19] report that these alterations, unlikely in dogs, were not specifically related to dislocation or subluxation of the femoral head but mainly to structural changes of the joint elements also noticed thickening of the femoral neck and bilateral flattening of the acetabulum. Osteoarthritis of the hip is characterized by osteophytes particularly at the edge of the acetabulum and around the femoral neck, and the femoral neck osteophytes are usually seen as a sclerotic line on radiographs [3]. Radiographically, cats with HD have greater remodeling of the acetabulum with minimal changes in the femoral neck when compared to dogs, [1]. The aim of this study was to evaluate the incidence of hip dysplasia in adult cats using radiographic examination and to correlate radiographic findings with Norberg Angle

\section{Materials and Methods}

Eighty-six cats were recruited during routine visits to the University State North Paraná in Veterinary Hospital in the period from January 2011 to January 2012 inclusion in this study. All were over 1 year old, and there was no sex bias. Criteria for exclusion were pregnancy or lactation, history of trauma or presence of contra-indications for sedation. After informed consent, the owners were interviewed, and clinical and orthopedic examinations performed on the cats to assess pain, range of motion and tenderness. Ventrodorsal radiographic projections of both hip joints were made under anaesthetic with propofol, with the hind limbs extended and slightly rotated medially, according to OFA (Orthopedic Foundation for Animals) guidelines. Norberg angle, articular changes and morphology were tabulated and correlated. To assess the Norberg Angle a template with circles of varying diameter was superimposed on the radiographs to determine the center of each femoral head. Then a line was traced through the centers of the femoral heads. The center of each femoral head was connected to the cranial-dorsal rim of the acetabulum and the angle made by on the medial side by the intersection of the 2 lines was the Norberg Angle.

The coverage of the femoral head was determined by a line drawn through the cranial and caudal dorsal acetabular rims relative to the center of the respective femoral head; being considered medial when this line was medial to the center of the femoral head; borderline when it crossed the center of the femoral head and lateral when it was lateral to the center of the femoral head.

\section{Results and Discussion}

Variables were normally distributed using KolmogorovSmirnov test ( $p>0.05)$. Different degrees of acetabular coverage and congruency were analyzed by Tukey's test Analysis of variance was used to correlate Norberg angle with the degree of coverage of the femoral head ( $p<0.05)$.Thirty-five $(35 / 86)$ cats showed some sign of discomfort during physical examination. Nine owners (9/56) of the incongruent cats reported some behavioral changes during anamnesis. Results were independent of sex and body condition ( $p>0.05$ ). Data shown in Table 1. The incidence of articular disease found in this study (56/86) was significantly higher than a previous study which only reported an incidence of $6.6 \%$ [10]. This suggests that HD has probably been underestimated or misdiagnosed previously. Medeiros Júnior. (2007) found an incidence of $40 \%$ dysplastic cats in their study. Milken [20], found Norberg angles varying from $89.75^{\circ}$ to $93.02^{\circ}$ in dysplastic cats, which is in accordance with findings of Langenbach et al. [21] who found Norberg angles varying from $84^{\circ} \pm 10^{\circ} \circ$ to $95^{\circ} \pm 5^{\circ}$. 
Table 1: Effect of congruency, sex, body condition and correlation of the acetabular edge with Norberg angle in 86 cats.

\begin{tabular}{|c|c|c|}
\hline \multicolumn{3}{|c|}{ Norberg angle } \\
\hline \multicolumn{3}{|c|}{ Mean (degrees) } \\
\hline \multirow{3}{*}{ Acetabular Coverage (n) } & Medial - cranial (18/86) & $90.61^{\circ} \mathrm{a}$ \\
\hline & Borderline-medial (50/86) & $97.08^{\circ} \mathrm{b}$ \\
\hline & Lateral - caudal (18/86) & $101.22^{\circ} \mathrm{C}$ \\
\hline \multirow[t]{2}{*}{ Sex (n) } & Female $(52 / 86)$ & $95.38^{\circ}$ \\
\hline & Male (34/86) & $98.32^{\circ}=$ \\
\hline \multirow[t]{3}{*}{ Body Condition (n) } & Normal $(66 / 86)$ & $96.15^{\circ}$ \\
\hline & Overweight (12/86) & $96.92^{\circ}$ \\
\hline & Underweight (8/86) & $99.25^{\circ}$ \\
\hline \multirow[t]{3}{*}{ Articular congruency (n) } & Incongruent (19/86) & $91.37^{\circ} \mathrm{a}$ \\
\hline & Slightly incongruent (37/86) & $94.30^{\circ} \mathrm{b}$ \\
\hline & Congruent $(30 / 86)$ & $102.60^{\circ} \mathrm{C}$ \\
\hline Total (n) & $(86)$ & $96.55^{\circ}$ \\
\hline
\end{tabular}

In our study the mean Norberg angle for poor to borderline femoral head coverage cats were $90.6^{\circ}$ and $97.8^{\circ}$ respectively, demonstrating that higher angles may be found in poorly covered femoral heads in cats. For those animals with signs of incongruity, mean Norberg angles varied from $91.37^{\circ}$ to $94.30^{\circ}$. For those cats with perfect congruence between femoral head and acetabulum, the mean Norberg angle was $102.6^{\circ}$, very different from the bigger Norberg angle found in those mildly incongruent cats. This suggests that the Norberg angle may not be a very reliable tool to predict hip incongruence. As in dogs, there was no influence ( $p>0.05$ ) of sex on the studied parameters, corroborating findings of Keeler et al. [22] Few animals in the study showed any discomfort during physical examination $(35 / 86)$ in contrast to the number of animals with hip incongruence $(56 / 86)$ or poor femoral head coverage $(68 / 86)$. One explanation for this is that the cats may have been anxious when they were examined in the hospital [1]. It is common for cats to show behavioral changes, such as reduced activity, due to chronic pain. In our study,

however, only a few owners of incongruent animals (9/56) reported any behavioral changes. It is possible that owners had failed to notice changes due to the lifestyle of their cats or that hip incongruence does not produce severe pain in most dysplastic cats. Although some authors suggest that inability or unwillingness to jump is common in dysplastic cats none of the cats with articular incongruity in our study had any reluctance to jump, climb on furniture or use a litter box.

\section{Conclusion}

The results of this study suggest that there is a high incidence of feline HD in Brazil, contradicting previous reports in the literature, and that the Norberg Angle should it only be used in conjunction with other findings in the diagnosis of HD. More studies are required to further define feline HD.

\section{References}

1. Alcântara DS, Vitorino Filho RNL, Verçosa BLA, Fonteles z GC, Souza JM, et al. (2008) Aspectos clínicos e radiográficos da displasia coxofemoral bilateral felina submetidas à tratamento medicamentoso: Relato de caso. Anais do Congresso Brasileiro de Medicina Veterinária, Gramado, Rio Grande do Sul (in Portuguese).

2. Atamaniuk W, Mazur J (2005) Frequency and degree of hip joint changes in purebred cats in the lower silesia region. European Association of Veterinary Diagnostic Imaging -12th Annual Conference Naples, p. 20.

3. Bennet D (2008) Cats do not suffer arthritis, do they? 33rd World Small Animal Veterinary Congress, Dublin p. 52-54.

4. Bennet D (2008) Feline osteoarthritis and degenerative joint disease (radiology). European Veterinary Conference, Amsterdam p. 179-180.

5. Caney S (2007) Feline arthritis. Veterinary Focus 3: 11-17.

6. Clarke S, Bennett D (2004) Feline osteoarthritis. 12th European Society of Veterinary Orthopaedics and Traumatology Congress Munich p. 14.

7. Clarke S, Bennett D (2006) Feline osteoarthritis: a prospective study. Journal of Small Animal Practice 47: 439-445.

8. Douglas Sw, Willianson Hd, Sistema Ósseo, Williamson Hd, Gavin Ma, et al. (1975) Diagnóstico Radiológico Veterinário. São Paulo p. 31-69.

9. Elices-Mínguez R (2009) Degenerative osteoarhritis. International Congress of the Italian Association of Companion Animal Veterinarians Rimini p.14.

10. Keller GG, Corley EA (1996) Hip dysplasia: Orthopedic Foundation for Animals: Data on the Maine Coon Cat. Maine Coon Breeders and Fanciers Association Scratch Sheet p.18.

11. Kolde Dl (1974) Pectineus tenectomy for treatment of hip dysplasia in a domestic cat: A case report. Journal of the American Animal Hospital Association Schaumburg 10: 564.

12. Langenbach A, Green P,Giger U, Rhodes H, Gregor Tp, et al. (1998) Relationship between degenerative joint disease and hip joint laxity by use of distraction index and Norberg angle measurement in a group of cats. Journal of the American Veterinary Medical Association, Schaumburg 213: 1439-1443.

13. lascelles Bd (2008) Incidence of feline DJD and what the radiographic changes mean. 14th European Society of Veterinary Orthopaedics and Traumatology, Munich, Germany, p. 126-127.

14. Medeiros Júnior Lc, Ajzen S, Keller Gg (2007) Avaliação radiográfica da ocorrência de displasia coxofemoral em gatos sem raça definida na cidade de São Paulo - Brasil. Revista Portuguesa de Ciências Veterinárias, Lisboa 102: 61-64.

15. Milken Vm (2007) Estudo radiográfico comparativo da displasia coxofemoral entre gatos da raça persa e sem raça definida. Tese (Doutorado em Medicina Veterinária) - Faculdade de Medicina Veterinária e Zootecnia da UNESP, Botucatu p. 29-40.

16. Ness Mg, Abercromby Rh, May C, Turner Bm, Carmichael Sca, et al. (1996) survey of orthopaedic conditions in small animal veterinary practice in Britain. Veterinary and Comparative Orthopaedics and Traumatology, Stuttgart 9: 43-52.

17. Patsikas Mn, Papazoglou Lg, Komninou A, Dessiris Ak, Tsimopoulos G, et al. (1998) Hip dysplasia in the cat: a report of three cases. Journal of Small Animal Practice Nova Jersey 6: 290-294.

18. Piermattei Dl, Flo Gl, Decampi Ce (2006) The Hip Joint. Small Animal Orthopedics ad Fracture Repairs Missouri pp. 461-511.

19. Piras A (2009) Feline Orthopaedics: Cats are not Small Dogs. $34^{\text {th }}$ World Small Animal Veterinary Congress São Paulo.

20. Smith Gk, Langenbach A, Green Pa, Rhodes Wh, Gregor Tp, et al. (1999) Evaluation of the association between medial patellar luxation and hip dysplasia in cats. Journal of the American Veterinary Medical Association 215: 40-45.

21. Voss k (2010) Joint Diseases in Cats - What do We Know? 35th World Small Animal Veterinary Congress Geneva, USA.

22. Wolf A (2007) Degenerative Joint Disease in Cats. Latin American Veterinary Conference Lima. 
ISSN: 2574-1241

DOI: 10.26717/BJSTR.2018.09.001731

Danilo Marques. Biomed J Sci \& Tech Res

(i) This work is licensed under Creative Commons Attribution 4.0 License

Submission Link: https://biomedres.us/submit-manuscript.php

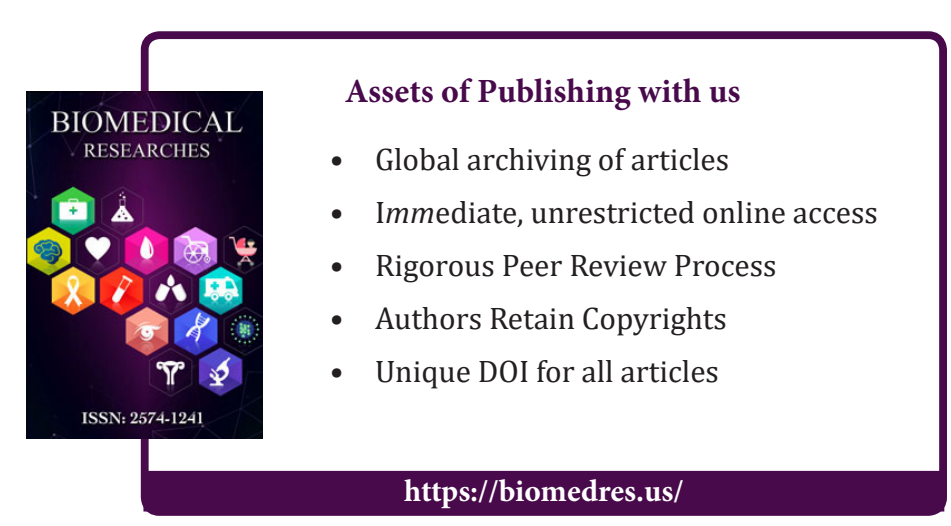

